\title{
SECONDARY OBSERVER EFFECTS: IDIOSYNCRATIC ERRORS IN SMALL-N SECONDARY DATA ANALYSIS
}

Nate Breznau, breznau.nate@gmail.com

\begin{abstract}
In this paper I extend the concept of observer effect to the realm of secondary data analysis. When analyzing what appear to be the same secondary data utilizing the same methods, macrocomparative researchers arrive at different results. I argue that this is a product of idiosyncratic variation directly or indirectly produced by the researcher. Even when this bias produces only small perturbations in interpretation or results, the consequences may be large for small-N analyses. Using an influential study by Brooks and Manza I analyze this secondary observer effect. Two replications of the practice of compiling seemingly identical secondary datasets produced variation. Reanalysis of the divergent values in these datasets and a second look at the original tables produces similar but not identical results. A rough calculation of the size of the secondary observer effect suggests that about a 0.32 standardized standard deviations across variable scores. Simulations of this size of secondary observer effect show that significant changes in findings occur.
\end{abstract}


There are a plethora of errors known to boggle social scientists. Statistical researchers manage many of these errors using modeling strategies such as latent measurement, weights, partitioning variances, and specifying distributions. Sometimes sources of error are intentional such as a survey respondent who purposefully lies or a researcher who fakes results. More often errors are unintentional for example a researcher who collects data in different emotional states, enters data inaccurately into a database or uses a method (via computer software) with unintended parameters, estimations or constraints in a statistical model. Although careful replication or reanalysis should make the latter set of errors identifiable there is a wholesale lack of such scrutiny in academia. This is true across all scientific disciplines and amounts to a replication crisis. This crisis is extensive in macro-comparative research where case numbers are low. Whereas experimental researchers do not expect to produce identical or even very close results via replication (Stanley \& Spence, 2014), secondary data analysts should expect this when they reanalyze publically available data with standardized statistical routines on computers. However, this is not the case.

In this paper show that different researchers attempting to analyze seemingly identical secondary data with the same methods arrive at surprisingly different results. I propose that idiosyncratic or subliminal variations occur across researchers and their practices. I label these small disturbances secondary observer effects (SOE). This lack-of-reliability in secondary data analysis is another danger to heed in addition to the well-known validity issues facing this realm of small-N, macro-comparative research (Beck \& Katz, 1995; Shalev, 2007) ${ }^{1}$. Instances of SOE occur when researchers make errors that are not readily attributable to methods or validity of

\footnotetext{
${ }^{1}$ I take general statistical definitions here that validity is the degree to which a model or variable actually tests or measures what the researcher claims and reliability is the degree to which results or measures are stable and similar when model tests or variable measurements are repeated.
} 
statistical models, for example during data acquisition and preparation, application of statistical routines, or interpretation and dissemination of results. In order to demonstrate some SOEs, I aim to replicate the work of Brooks and Manza (2006, hereafter "B\&M") with a high academic visibility among the top 100 most cited articles in the American Sociological Review. Their study is ideal because of its ostensible validity employing a somewhat uncontroversial theory that democracy helps facilitate public preferences to impact social outcomes, it has a small-N of 43 cases nested in a smaller-N of 15 countries, and already has one replication by another social researcher. Adding my own work here I have two independent replications of the B\&M dataset fit for reanalyzing and identifying secondary observer effects.

The paper proceeds with a discussion of the observer effect in general and then distinguishes between primary and secondary forms. Then it briefly discusses SOEs conceptually, aims to quantify their size and finally demonstrates what impact they might have on results of the B\&M study using simulations. Based on the conceptual and empirical examples I compile a non-exhaustive list of secondary observer effects. Finally I conclude with clear recommendations about what all social science disciplines should do to stave these effects, if not the replication crisis in general.

\section{The Observer Effect}

The capacity of an observer to bias data comes in two broad categories. One is an observer error and the other an observer effect. Observer errors are well known to occur during primary data collection and lead to altered results due to cheating, bias/favoritism or drift (McCall, 1984). They may be identified and controlled for, except when they stem from the principal investigator. For example, cheating was a mainstay of infamous and poser social 
psychologist Mr. Diederik Stapel who falsified data throughout his career publishing fake results in over 50 peer-reviewed articles. Prior to uncovering his acts, the observers working on his experiments were unaware of his cheating essentially because there was no one directly observing him (Levelt, Noort, \& Drenth, 2012). This is an example of extreme observer error due to its ethical dearth and low risk of detectability ${ }^{2}$.

The observer effect occurs instead when observers influence the objects of their research without intention and these objects become a source of error. The observer effect was brought into the limelight originally as the Hawthorne Effect named after a series of experiments on industrial worker productivity from 1924 to 1933 in the United States. Despite increasingly harsh and unusual working conditions the workers in the Hawthorne studies maintained or even increased productivity. The researchers concluded that the levels of worker productivity were positively influenced by the presence of observers. The theorized mechanism was that the workers were aware that their performance was under evaluation, especially as they interacted regularly with the observers, leading them to be ever-productive across changing working environments, management and social relations (Roethlisberger \& Dickson, 2003). If the observers in this study were the cause of sustained or increased worker productivity then this was a case of primary observer effects (Barnes, 2009).

This definition of primary observer effects to date is identical with that of observer effects referring to research on human subjects. For example in fieldwork such as ethnographic and participant observation research a primary observer effect is incorporated into the research design where observers are aware of their potential influence during intentional and often

\footnotetext{
${ }^{2}$ Although this is one of the largest known cases it is not the only one (Stanley \& Spence, 2014; van Kolfschooten, 2014).
} 
extensive interaction with human research subjects (Bell, 1999). Other primary observer effects known to survey researchers are often unwanted. In the U.S. General Social Survey for example, race and sex of interviewers led to significantly different responses by race and sex of respondents respectively (Liu \& Stainback, 2013; Schaeffer, 1980). In a Belgian study, college students gave more socially desirable responses to sensitive questions when researchers personalized communications (Heerwegh, Vanhove, Matthijs, \& Loosveldt, 2005). Also in the U.S. a powerful demonstration of social desirability showed that respondents over-report church attendance by roughly $50 \%$ when interviewed in-person versus self-completion questionnaires (Presser \& Stinson, 1998). These examples of primary observer effects have to do with primary data because the primary data are biased by the presence and behaviors of researchers.

I propose herein that primary observer effects are one of two subcategories of observer effects. I theorize the additional existence of secondary observer effects (SOEs) where the observers themselves are a source of error or bias unassociated with the actions of their subjects of study. This occurs during the construction of macro-comparative datasets from various public sources and the analyses of these data and in this paradigm there are no active human subjects under research but only passive secondary data. Yet observers doing nothing out of the ordinary in macro-comparative research still face divergent results and this paper seeks to identify and explain this. I suggest that SOEs are a source of variation in outcomes where identical results are expected; i.e. while analyzing ostensibly the same data using the same statistical methods.

\section{Finding Secondary Observer Effects}

This research has a qualitative launching point. In conducting macro-comparative social research I discovered irregularities, I also discovered that I was not alone in this experience and 
this paper is my first attempt to explain this. Quantitative researchers working with small-N aggregated datasets will quickly relate to the following illustrations. Imagine conducting research where a strong theory predicts that in countries an average quality of the public $\mathrm{x}$ leads to a country-level outcome $y$ after considering the independent effects of other sociopolitical variables $z_{1}$ and $z_{2}$. A researcher models these relationships using aggregate data from some secondary sources and finds a significant impact of $\mathrm{x}$ on $\mathrm{y}$ under these exact conditions. Assuming the researcher's theory for how $\mathrm{x}$ impacts $\mathrm{y}$ passes reviewer scrutiny this significant hypothesized effect (i.e. a rejection of the null hypothesis) meets the general criteria for publication in a peer-reviewed journal (Sterling, Rosenbaum, \& Weinkam, 1995).

Assume validity for this imaginary example meeting the improbable condition that the theoretical model is unquestionably valid and that the sample of countries allows for variableoriented probabilistic analysis ${ }^{3}$. Now imagine some additional conditions where the data are 40 country-cases, $x$ and $z_{1}$ are individual-level data aggregated to the country-level, and $z_{2}$ is a country-level variable taken from an international data bank. With the validity of theory assumption, these additional conditions should not change the publication of the result ${ }^{4}$. Now imagine two final conditions that are critical to understanding secondary observer effects: (1) that the researcher accidentally downloads the data for variable Z2 for the year 2001 when the analysis is for 2000 , and (2) that the researcher aggregates individual data from 40 countries to country-mean scores after removing cases that had missing data on individual-level outcome y and control $\mathrm{Z}_{1}$.

\footnotetext{
${ }^{3}$ The author is well aware of validity problems with small-N research but these are outside of the present discussion (Goldthorpe, 1997; Shalev, 2007).

${ }^{4}$ Many examples with 8-20 cases abound in the field of social policy research (Bradley, Huber, Moller, Nielsen, \& Stephens, 2003; Brady, Beckfield, \& Seeleib-Kaiser, 2005; Castles \& Obinger, 2007; Castles, 2002; Hicks \& Kenworthy, 2003; Hicks \& Swank, 1992; Huber, Ragin, \& Stephens, 1993; Iversen \& Cusack, 2000; Iversen \& Stephens, 2008; Kenworthy, 1999; Mehrtens III, 2004; Skocpol \& Amenta, 1986, pp. 141-42; Swank, 1998).
} 
Considering condition (1), if the variable measured at the wrong year is something like median-income, population or corruption perceptions by country then model results should not change as these are relatively stable measures. The autocorrelation of such variables between consecutive years is nearly 1 except in special cases of war or economic disaster, and the annual changes of these and many other country-level measures are tiny. However, this research has only 40 country-cases and with such limited information and statistical power the models might be sensitive to such small disturbances due to the large biasing potential of measurement errors, non-random error distributions, and outliers (Kittel \& Winner, 2005; Kittel, 2006; Van der Meer, Te Grotenhuis, \& Pelzer, 2010). If this small change makes the difference between a significant impact of $x$ on $y$ versus not, then this is an example of a secondary observer effect. A counterargument here might be that this is merely sloppy science and researchers should be responsible for never making such a mistake. Although I argue that simple research hiccups of this nature are common, I will entertain this counter-argument and propose an alternative to condition (1) where the international data bank accidentally puts the 2001 data in the place where the 2000 data should be and the researcher remains oblivious to this fact leaving an honest and non-sloppyscience error potentially biasing results. In either case, the research was merely following what cross-national comparative social scientists do on a regular basis (Bollen, Entwisle, \& Alderson, 1993). The existence or severity of this problem can only be identified using simulation or replication unless the researcher realizes the mistake at some point which would require an uncommon self-reanalysis practice.

Condition (2) is realistic if we imagine the researcher is also interested in reverse causality and is estimating an alternative (multilevel) model of aggregate measure y on individual measure $\mathrm{x}$ with individual control $\mathrm{z}_{1}$, and set up the data first at the individual-level 
with listwise deletion before later collapsing and modeling the effect of $\mathrm{x}$ on $\mathrm{y}$. If there are 1,000 cases in a given country and 100 are listwise deleted for reasons of being missing completely at random then sampling theory predicts and simulations confirm that collapsing the individuallevel data to the country-level with or without including the 100 cases will not matter (Winship $\&$ Radbill, 1994). For example if the mean of some individual-level variable across these 1,000 is 5 on a 0 -to- 10 scale and the standard deviation (s.d.) is 1 , then the mean and s.d. of the 100 dropped cases should also be 5 and one. However, random probability could lead to the unlikely event that the mean of those 100 cases is different from five. Given a normal distribution, the likelihood of the mean of the 100 dropped cases being 4.8 or less (or 5.2 or more) is $1.75 \%{ }^{5}$. Imagine that this unlikely condition is met. So the researcher drops 100 cases with an average score of 4.80 and this shifts the country-level mean from 5 up to 5.02. This is a tiny difference, but in a statistical model this difference is barely larger than two-digit rounding-error and does not matter. But what if it did? This would be a theoretical case of a secondary observer effect because the observer was following statistical practices that would have no noticeable impact on large-N research. However, an arbitrary or idiosyncratic decision to collapse before or after dropping missing cases suddenly makes the difference between significant results and not in this imaginary SOE example.

I argue that the imaginary scenarios presented above are within the common practices of macro-comparative research. For example the Organization for Co-operation and Development (OECD) is a heavily utilized source for country-level data relating to social, economic, political and demographic measures. The OECD regularly updates its measures when it receives new

\footnotetext{
${ }^{5}$ Sampling distribution mean $=($ sample $)$ population mean $=5$; standard deviation of the sample distribution is the square root of $1 / 100$ minus $1 / 1000=0.09486$ (truncated); $\operatorname{Probability}(X \leq 4.8)=\operatorname{Pr}(Z \leq(4.8-5) / .09486)=\operatorname{Pr}(Z \leq$ $2.1084)=0.0175$.
} 
information or engages in corrections concerning previously published data. Thus, acquiring the OECD measure of per capita GDP in 2003 would not lead to identical data if it were downloaded in 2010 compared with 2014 for example. For 30 countries the correlation between these two different download years of the same measure is 0.994 (OECD 2010, 2014 author's own downloads and calculations). This correlation is essentially 1 and should not alter the results of models using either measure, but I test this before making such a conclusion for the small-N setting.

\section{Replication and Reanalysis}

The nature of this paper is a combination of replication and reanalysis (see Herrnson, 1995) mixed with my own experience in macro-comparative social science. Thus in the current research I was initially both a researcher and the object of study. Working as a social scientist I attempted to replicate the dataset of B\&M and to my chagrin I could not, thus I began to analyze myself to discover why not. In this reflexive process I inspected the dataset of another researcher who published a critique of B\&M and I realized that he also was unable to exactly replicate their dataset either and furthermore his data were different from mine. The surprising difference between three datasets constructed to measure the same thing from the same sources was a process of identification of secondary observer effects in macro-comparative research. This work has an inductive logical starting point where different researchers were unable to measure and reproduce identical results when measuring the same data leading to the conclusion that differences in researchers leads to different results. I thus have a grounded theory about the existence of SOEs based on observing myself working as a small-N macro-comparative 
researcher. I admit that my selection of B\&M's work was not random and my identification of SOEs followed no research plan because I did not expect them until after they were found.

Based on my experiences my goal became to identify, quantify and simulate secondary observer effects. To do this I first replicate the dataset compiled and utilized by B\&M (2006). Their variables include many OECD country-level measures. Kenworthy (2009) does the other replication of their dataset and currently shares it publically. Except for descriptives I am unable to compare either of our datasets to the original one of B\&M because they were unwilling to share $^{6}$. Next I attempted to reproduce the linear impact of public policy preferences on social welfare spending in these seemingly identical datasets. Originally I expected this to be equivalent to a reanalysis of $\mathrm{B} \& \mathrm{M}$ data leading to exact reproduction of their results because all measures are taken from publically available, carefully cited secondary sources. In order to ensure comparison of all measures and to rule out any re-scaling done by the secondary sources I rescaled all variables in both replicated datasets to have identical means and s.d.'s as B\&M's variables.

Where identical results are expected I find differences. Evidence of SOE is in these differences. The descriptive statistics diverge slightly across all three datasets (see Appendix 1). Using linear models seemingly identical to the one utilized by B\&M, I find significance mostly where they did, but coefficients differed in magnitude. This information leads me to a closer scrutiny of all versions of results. Table 1 presents these different results.

\footnotetext{
${ }^{6}$ Of three separate emails to the authors over the course of 2010-2012 one was unanswered and two were met with refusals telling me that I should use my own sense in reproducing their measures. I will not fully fault them for this because the provision in the American Sociological Association's policy on data sharing states: "Sociologists who do not otherwise place data in public archives keep data available and retain documentation relating to the research for a reasonable period of time after publication or dissemination of results" (ASA 1999: 16). Without an explicit definition of 'reasonable period' by the ASA, they are not in violation of the code.
} 


\section{[TABLE 1 ABOUT HERE]}

The original results of B\&M (2006) are in the first two columns of Table 1 as metric regression coefficients and robust cluster standard errors. A single significance star indicates which coefficients are significantly different from 0 , two-tailed at $\mathrm{p}<.05$. The subsequent two columns are results of the same model run on Kenworthy's data and then the final two columns on my data. Model I in the top panel of Table 1 represents direct effects of the main variables of interest and Model II in the lower panel represents a potential indirect path of these effects through religious and political institutions exactly following Brooks and Manza. I remind the reader here that I focus only on reliability due to SOE and I do not question validity. Looking at results across the datasets reveals minor variation in size and significance of the metric coefficients for the control variables. For the main test variable of social policy preferences the size, but not significance varies by dataset. Thus the main finding of B\&M initially appears to hold in all three datasets where social policy preferences are a significant predictor of social welfare spending, and this effect is significantly smaller in liberal democracies than social and Christian democracies as shown by the interaction term Social Policy Preferences $*$ Liberal Democracy. These results seem to suggest that SOEs are negligible here.

A closer consideration suggests that this conclusion is hasty. I report the analysis of the datasets produced by Kenworthy and myself in the same way as B\&M, namely looking for significant effects of the social policy preferences measure and its interaction with liberal democracy. Brooks and Manza concluded originally that the, "...interrelationship between policy preferences and liberal democracies, the estimate of $-2.35\left(\right.$ s.e. $\left.=.93^{7}\right)$ is clearly non-negligible,

\footnotetext{
${ }^{7}$ This s.e. is different from the one reported in Table 1 below. This is not an error of the author. The original B\&M article inconsistently lists s.e. of "0.93" as quoted here and "0.92" in their Table 4 on p. 487.
} 
and the coefficient's negative sign indicates that the effect of social policy preferences on welfare state spending effort is smaller within liberal democracies in comparison to social and Christian democracies" (2006b, pp. 486-87). They were referring to Model I, but this conclusion applies to Model II as well. Their conclusion is also applicable to both of the replicated datasets when conducting simple subtraction of the coefficient for social policy preferences and the interaction to yield the Net Liberal Democracy Effect. Using this technique yields an effect of 1.35, 1.47 and 0.44 in Model I and 0.88, 1.00 and 0.18 in Model II as shown in the bottom italicized row in each model. Although B\&M's model confirms that these are "non-negligible" effects due to their significant difference from 0 , the size of the effect is close to only one-third the size of the impact in social and Christion democracies in B\&M's models. Whereas B\&M observe this effect and admit that it "varies substantially" by regime type (p. 487) they do not use it to change their main argument which is that countries spend more (or less) on welfare due to greater (or lesser) public support. I ask myself if this is the conclusion I would draw from this data.

In order to answer this question I would need to take an extra critical step. My training tells me to use the smaller effect in liberal democracies as evidence against the B\&M hypothesis. Without going into the validity of their theory I focus on the reliability of their (or my own) interpretations of these results. I find that B\&M's common usage of a simple interaction sheds light on an area rife with SOE potentials. They chose to present and focus on significant differences between the coefficients for Social Policy Preferences compared with Social Policy Preferences*Liberal Democracy (Table 1; B\&M 2006:p. 487) signaling that the two types of democracies have different preferences-to-policy processes but they concluded that there is an effect in each type of democracy. If I want to reliably make this conclusion I would want to know whether the effect in liberal democracies is significantly different from zero. 
Although this is a subtle difference in testing it is important as it carries the potential to change the results. It is not invalid to report the results the way B\&M do, but it is again an example of researcher idiosyncrasies in taking steps to interpret results for which I have a particular methodological training and process (Aiken \& West, 1991; Braumoeller, 2004). I argue that these are SOEs. Although blatant statistical error due to misinterpretation happens with interactions (Macdonald, 2011), this presentation and interpretation of results is more of a subtle difference. Although the statisticians and mathematical social scientists may cringe, my own approximation of what social science does is not predominantly robust statistical methodology and the SOE that I identify with the interaction term here is what I would label normal across social science disciplines. Thus, looking at the italicized row in each model reveals that using my seemingly identical data would have led B\&M to conclude that policy preferences only have a significant impact in Christian and social democracies (coefficient for Social Policy Preferences) but not liberal democracies (coefficient for Net Effect in Liberal Democracies) in one out of three versions of the datasets ${ }^{8}$.

Here I conclude that the bias of SOE in this reanalysis appears negligible, but a slight framing shift in how a researcher such as myself might view the results from significant differences between coefficients to significant differences from 0 would render 1 out of 6 potential impacts $(16.7 \%)$ of policy preferences on welfare spending to be false given that 2 of the 12 coefficients ( 2 effects per model $* 2$ models per dataset*3 datasets) are not significant. As I assume validity (i.e. the statistical models are identical) then only interpretation or dataset differences explain these divergences in results.

\footnotetext{
${ }^{8}$ I cannot test the significance of B\&M's effect in liberal democracies reported in Table 1 at 1.35 , because they do not report the standard error but their testing of its significance is implied in their writing (2006:487).
} 
I aim to explain the size of SOE to identify how the aforementioned differences came to being. Table 2 presents descriptive statistics of the differences between separate measures taken from Kenworthy and myself which are seemingly identical based on the sources B\&M cite.

\section{[TABLE 2. ABOUT HERE]}

The left most column in Table 2 refers to variables that were subtracted from one other to produce difference scores. All variables were linearly transformed to have means of 0 and equal standard deviations to allow accurate comparison, thus all means of differences are 0 as shown in the column labeled mean. The standard deviation of the 43 difference scores produced via subtraction are in the next column and further to the right a minimum and maximum difference are reported to give the spread of these differences.

I include some other versions of the measures in play in the B\&M research in order to give the best possible estimate of the size of secondary observer effects. The first is listed in Table 2 under Social Welfare Spending as "CWS" and this is a measure of social spending taken from the Comparative Welfare States Dataset which was constructed by the same team of researchers cited by B\&M as their intermediary source for the OECD data they utilize. Although the CWS is no longer publically available I downloaded a copy in 2010 . The overall welfare state spending measure from the CWS is not identical to B\&M in terms of mean and standard deviation $(\mathrm{B} \& \mathrm{M}$ mean $=21.53, \mathrm{~s} . \mathrm{d}=5.23 ; \mathrm{CWS}$ mean $=21.50$, s.d. $=5.41)$ but it is extremely close and I assume that this is the source of their dependent variable and probably some SOE explains the slight difference. Regardless, it provides one more opportunity to introduce SOE into this calculation.

The second alternate versions are for the policy preferences variable. The illustration I gave in the preceding section of dropping cases before generating country-means illustrates one 
of many reasons that I credit for my failure to reproduce the same variable from the International Social Survey Program (ISSP) that B\&M report. They claim they generate "factor scores" (2006:482) for their social policy preferences variable. However, this ubiquitous practice across social science disciplines could involve a variety of strategies giving another opportunity for SOE to enter the model. Given their mean of -0.01 and s.d. of 1.88 , I am unable to determine exactly what steps they took, for example it is unclear if they used an additive score, average score, predicted factor, predicted principal component, or application of maximum likelihood in estimation or for interpolation. It is further unclear if they took steps to construct a scale before or after collapsing and whether they incorporated weight. As B\&M utilized only two items the various options for creating scales should not matter too much because each item in an additive score or latent factor has essentially identical influence on and uniqueness from the final scale ${ }^{9}$ Thus, if B\&M took the mean, common predicted factor, or principal component for example, all three techniques produce measures with near perfect correlations - the latter two are correlated at 1.0 and they have internally identical correlations of each of the two items with the predicted factor, while the former leads to slightly divergent contributions of each item with the mean but correlating at 0.99 with the predicted factors (author's calculations). In my investigation into this topic two things that are unmentioned in the B\&M text strike me as further areas for SOE, (1) whether they produced their scale scored before or after collapsing the data to country-means, and (2) whether they used weights when collapsing the data.

I discovered that varying both of the above conditions (1) and (2) leads to somewhat divergent scores. As I know of no standard practice in small-N macro-comparative research I

\footnotetext{
${ }^{9}$ Using factor analysis techniques on three or more items allows the contributions and uniqueness to vary for each item, not to mention that it is possible to extract more than one factor.
} 
assume that researchers such as myself, Kenworthy and B\&M are using scale construction choices at 'random' based on what they happened to learn in their methods training. In large-N studies the correlations of 0.99 produced by these seemingly innocent choices will have no impact on results at 2 decimal places, but small-N research is a different animal. In Table 2 the reported differences may appear large but they leave the correlations between seemingly identical measures very high as shown in the last column.

The variables in Table 2 are labeled to save space: For Social Policy Preferences, Kenworthy $(B \& M)$ refers to the data supplied to Kenworthy by B\&M for his 2009 presumably identical to B\&M's original variable; Post Factor refers to weighting and collapsing of the two scale items into country-means and then taking a predicted factor score for each country-time point from common factor analysis and linear prediction consistent with my own idiosyncratic methods; Pre Factor refers to generating a factor score for each individual using the same common factor analysis method and then weighting and collapsing these scores to country-time point means; and Unweighted refers to a variable generated in every other way the same as Post Factor but without using the ISSP's sample weighting.

The bottom three rows of the table summarize the average standard deviation for the spending and preferences variables only and then summarize spending, preferences and all controls in the bottom row. This bottom row reports difference scores calculated from versions of all variables standardized to a mean of 0 and s.d. of 1 . This is the only way to directly compare them. I take the average standard deviation of 0.32 to represent the approximate size of SOE for this research. 


\section{Simulation of Secondary Observer Effects}

Having identified size I next utilize simple Monte Carlo simulations to gauge the risk this SOE poses to the reanalysis of findings by Brooks and Manza. In the first simulation stage I reanalyze Kenworthy's and my datasets while simulating a pseudo-random normally distributed error in the measurement of both the dependent variable of social welfare spending (s.d. $=1.88$, see Table 2) and independent variable of social policy preferences (s.d. $=0.24)$. In this basic first step I leave all the control variables in their original measurement as replicated by myself and Kenworthy. Although I have reason to believe that the risk of SOE is equal for all variables, I seek to give a parsimonious account of SOE where only the variables of interest are affected. Thus, Simulation A only introduces an SOE error term for spending and preferences. I run 1,000 simulations of the SOE error for each of nine different paired versions of dependent and independent variable leading to 9,000 simulations for each Model. Although it provided another way of triangulating the size of secondary observer effects, I do not use the Unweighted measure as this could arguably be an issue of validity and I want to fix validity in order to focus on reliability. The results of this simulation are in Table 3, Simulation A.

Given that macro-comparative models are often over-fitted, or can be heavily biased by a lack of degrees of freedom, I simulate SOE for all variables in the models simultaneously. This means that each variable is assigned its own pseudo-random normally distributed error with s.d. equal to 0.32 standardized deviations of the variables metric standard deviation. The same modeling strategy otherwise applies leading to 9,000 simulations for each model. These results are presented in Table 3, Simulation B.

[TABLE 3 ABOUT HERE] 
In Table 3 I report only the tests that the coefficients are different from 0 at $p<.05$ twotailed. I assign H1 to represent the hypothesis that there is an effect that is significantly different from 0 of social policy preferences on welfare state spending, i.e. the Social Policy Preferences coefficients presented in Table 1 . Then $\mathrm{H} 2$ represents a predicted significant impact of social policy preferences in liberal democracies that is different from that of the coefficient in social and Christian democracies, i.e. the Social Policy Preferences*Liberal Democracy coefficients in Table 1. Finally, H3 represents the unreported test of the hypothesis that the coefficient for social policy preferences in liberal democracies is significantly different from zero, i.e. the Net Liberal Democracy Effect coefficients in Table 1. The column values below H1-H3 represent percentage rejections of the hypothesis out of $\mathrm{N}$-simulations.

Looking at Model I in Simulation A the main story of H1 remains nearly unchanged. The impact of social policy preferences in social and Christian democracies is robust to secondary observer effects at only a $1 \%$ rejection rate. However, looking at $\mathrm{H} 2$, there is a $28 \%$ failure rate that social policy preferences have a significantly different impact in liberal democracies versus social or Christian democracies. How disconcerting is this? If these effects are the same in both types of democracies it which would provide some support of B\&M's theory which specifies that in all democracies there is an effect. Looking at results for $\mathrm{H} 3$ this is not the case, in fact the impact of social policy preferences in liberal democracies is not significantly different from zero $62 \%$ of the time. Simulating SOEs based on their measured size in practice leads to the conclusion that B\&M's theory does not apply to liberal democracies (e.g. the United States, United Kingdom, Australia, New Zealand or Japan). This is a massive change to the story they tell in their article and suggests that SOEs should not be taken lightly. 
The remaining rows of the table read in a similar way and in fact the impact of SOE becomes worse. In Model II there are 2 more variables and thus more chances for error and less degrees of freedom. For Simulation A the rejection of $\mathrm{H} 1$ increases from $1 \%$ to $16 \%$, and the others increase as well. The row that combines results from Models I and II helps to give an average given that I have no grounds for prioritizing one model over the other. Ultimately simulating SOE for all variables, which captures the empirical reality I observe between these three dataset replications, leads to nearly outright rejection of all findings. For example the combined Models I and II in Simulation B show that H1 is rejected 29\% of the time, H2 loses $66 \%$ of the time, and $\mathrm{H} 3$ proves to be wrong in $81 \%$ of the 18,000 cases.

\section{Results Summary}

I demonstrate through two replications of a cross-national aggregate dataset and analysis that SOEs heavily impact reliability. By holding validity constant in the B\&M theory and modeling methods I was able to empirically identify SOE and run a simulation to gauge this problem's severity. In the most conservative estimates SOE biases the results of B\&M (in a yet unspecified direction) roughly $28 \%$ of the time shown in Simulation A, Model I, H2. However, correcting for the SOE of interpretation of interaction effect this jumps to a $62 \%$ rejection of B\&M's hypothesis (A,I,H3). In the worst case their hypothesized effect would be rejected $81 \%$ of the time (B,I\&II,H3). This is evidence of the gravity SOE poses to macro-comparative research. It appears that smaller-N makes worse. Model II, having less degrees of freedom due to the addition of two more control variables, is less reliable than Model I and this is evidence that the smaller-the-N relative to the number of variables, the greater the SOE threat. 


\section{Conclusion}

I demonstrate a secondary observer effects (SOEs) in order to move macro-comparative research forward methodologically. This is another error in macro-comparative research that is not easily identifiable statistically and instead comes from the qualities of researchers and their idiosyncratic behaviors while conducting research. This exploratory step should open the door for further identification and understanding of this phenomenon as distinct from primary observer effects and other validity issues which are outside of the current scope (Beck \& Katz, 1995; Bollen, 1989; Kittel, 1999). A next step should be to randomly sample small-N studies in order to get a truly random estimate of SOE, as mine is taken out of convenience and I am cautious to generalize from this single example. In this particular example I am also cautious to criticize B\&M because their work is at once controversial and common in macro-comparative research and if anything the same criticisms of their work could and should be applied to all others (Brooks \& Manza, 2006a; Myles, 2006), in fact to their credit they attempt to improve upon previous techniques by employing as many countries as possible, tests for heteroskedasticity, and a robustness check.

Another concern in the current study is that a large portion of SOE in this case is due to the differences in secondary data measures, mostly in OECD data. Social welfare spending is particularly tricky because it is an aggregate measure of spending on more than nine distinct domains within each country including pensions, health care, unemployment, employment and much more. Given great variation in accounting practices by country, this variable may be uniquely susceptible to variation over time in the OECD database. For example, the most extreme case in the current study was Switzerland which differed between data sets on social welfare spending at 17.85 (CWS) compared with 26.41 (OECD 2010) for the same year of data. 
This is no longer idiosyncratic or a product of small yearly changes, something large clearly changed in the reporting of or the way that the OECD estimates spending in Switzerland. Researchers are not expected to be aware of the OECD's internal data maintenance and therefore they are not at fault for this. This may be an extreme case and future analyses should check if SOE is as extensive in other data sources and more stable country-level measures.

I propose that SOE theoretically depends on the qualities of a researcher such as research timing, methods training, pedantic research practices, and potentially academic discipline and software of choice although these need to be explored in future work. I make the practical assumption that we cannot know the precise size of SOE because we do not have a large random sample of researchers performing replications and reanalysis of a large random sample of all published and unpublished small-N findings. This leads to the conclusion that we should assume that small-N macro-comparative studies may be SOE biased. With this assumption we can move forward to dealing with it. In many disciplines the realm of macro-comparative researchers is small, networked and has niche outlets for publications. Thus communicating to each other the threat of SOE and what to do about it is important to the sustainability of our research, just like the need for utilizing improvements in statistical methods to deal with the known validity issues facing small-N research. I have three recommendations that I propose to circulate among macrocomparative social researchers.

First, all journals and at least those who claim to be 'top' journals should add a methods reviewer to the peer-review process in cases where small-N secondary data are utilized who is given only the concepts and theoretical model and then asked to (re)produce the findings. This would bring to light the reliability issue of SOE and have the added bonus of bringing model 
validity into focus as I assume that different researchers might also choose different modeling strategies to test the same hypotheses.

Second, a technical appendix should be required of small-N macro-comparative research (and probably all statistical research). This should be published online along with the journal article as server storage space is nearly negligible in cost. This would allow others to identify what idiosyncratic or other types of biases were introduced into the work by the researchers. As Kenworthy (2007, p. 344) himself points out: "Sometimes we miss things no matter how hard we look". This is somewhat analogous to the open peer reviewing movement taking place in the hard sciences as a solution to these kinds of problems, although authors are highly reluctant to take part (Editors, 2006).

Third and along the same lines, all data should be shared except where it cost substantial funds to acquire it, then the sharing should proceed but at a price to the researcher asking for access. Overall this sharing and transparency can only vastly improve the work that we all do. Humility and acceptance that no research or writing is free from errors will allow genuine scientific learning to take place otherwise we will be stuck encumbered by our own career prospects if not egos getting in the way.

These simple steps will vastly improve the nature of social science which may be the least reproducible of all sciences. It will certainly reduce or remove the element of chance in having results that are an artifact of secondary observer effects in addition to helping to alleviate the replication crisis as it manifests in secondary data analysis where we expect that results are reproducible and should be able to identify when they are not. 
I offer a final recommendation that secondary data sources such as the OECD should provide information on the timing and qualities of changes to their data. This would greatly assist researchers and reduce some secondary observer effects.

\section{Secondary Observer Effects}

Based on my experiences in researching this paper I identified the following nonexhaustive list of secondary observer effects that small-N macro-comparative researchers should be weary of if not all secondary data analysts in general.

- Differences in the same measures taken from the same sources

- Differences in the same measures taken from general techniques such as factor analysis or weighting (and possible in any other standard/normal research practices)

- The process of aggregating data generates a plethora of opportunities for SOEs

- Researchers draw different conclusions given the same findings, especially relevant to hypothesis testing with interactions

- An increasing threat of SOEs with decreasing degrees of freedom (i.e. more variables/less cases)

\section{References}

Aiken, L. S., \& West, S. G. (1991). Multiple Regression: Testing and Interpreting Interactions. Newbury Park: Sage Publications.

Barnes, B. R. (2009). The Hawthorne Effect in Community Trials in Developing Countries. International Journal of Social Research Methodology, 13(4), 357-370. doi:10.1080/13645570903269096 
Beck, N., \& Katz, J. N. (1995). What to do (and not to do) with Time-Series Cross-Section Data. The American Political Science Review, 89(3), 634-647. Retrieved from http://www.jstor.org/stable/2082979

Bell, E. (1999). The Negotiation of a Working Role in Organizational Ethnography. International Journal of Social Research Methodology, 2(1), 17-37. doi:10.1080/136455799295168

Bollen, K. A. (1989). Structural Equations with Latent Variables. New York, NY: Wiley.

Bollen, K. A., Entwisle, B., \& Alderson, A. S. (1993). Macrocomparative Research Methods. Annual Review of Sociology, 19, 321-351. doi:10.2307/2083391

Bradley, D., Huber, E., Moller, S., Nielsen, F., \& Stephens, J. D. (2003). Distribution and Redistribution in Postindustrial Democracies. World Politics, 55(2), 193-228.

Brady, D., Beckfield, J., \& Seeleib-Kaiser, M. (2005). Economic Globalization and the Welfare State in Affluent Democracies, 1975-2001. American Sociological Review, 70(6), 921-948. Retrieved from http://www.ingentaconnect.com/content/asoca/asr/2005/00000070/00000006/art00003

Braumoeller, B. F. (2004). Hypothesis Testing and Multiplicative Interaction Terms. International Organization, 58(04), 807-820. Retrieved from href="http://dx.doi.org/10.1017/S0020818304040251

Brooks, C., \& Manza, J. (2006a). Reply to Myles: Theory and Methods for Comparative Opinion/Social Policy Research. American Sociological Review, 71(3), 499-502. doi: $10.2307 / 30039002$

Brooks, C., \& Manza, J. (2006b). Social Policy Responsiveness in Developed Democracies. American Sociological Review, 71(3), 474-494. doi:Article

Castles, F. G. (2002). Developing New Measures of Welfare State Change and Reform. European Journal of Political Research, 41(5), 613-641. Retrieved from http://dx.doi.org/10.1111/1475-6765.00024

Castles, F. G., \& Obinger, H. (2007). Social Expenditure and The Politics of Redistribution. Journal of European Social Policy, 17(3), 206-222. Retrieved from http://esp.sagepub.com/content/17/3/206.abstract

Editors. (2006). Peer Review and Fraud. Nature, 444(7122), 971-972. Retrieved from http://dx.doi.org/10.1038/444971b

Goldthorpe, J. H. (1997). Current Issues in Comparative Macrosociology: A Debate on Methodological Issues. Comparative Social Research, 16, 1-26. 
Heerwegh, D., Vanhove, T., Matthijs, K., \& Loosveldt, G. (2005). The Effect of Personalization on Response Rates and Data Quality in Web Surveys. International Journal of Social Research Methodology, 8(2), 85-99. doi:10.1080/1364557042000203107

Herrnson, P. S. (1995). Replication, Verification, Secondary Analysis, and Data Collection in Political Science. PS: Political Science and Politics, 28(3), 452-455. Retrieved from http://www.jstor.org/stable/420302

Hicks, A. M., \& Kenworthy, L. (2003). Varieties of Welfare Capitalism. Socio-Economic Review, 1, 27-61.

Hicks, A. M., \& Swank, D. H. (1992). Politics, Institutions, and Welfare Spending in Industrialized Democracies, 1960-82. The American Political Science Review, 86(3), 658674. Retrieved from http://www.jstor.org/stable/1964129

Huber, E., Ragin, C., \& Stephens, J. D. (1993). Social Democracy, Christian Democracy, Constitutional Structure, and the Welfare State. The American Journal of Sociology, 99(3), 711-749. Retrieved from http://www.jstor.org/stable/2781288

Iversen, T., \& Cusack, T. R. (2000). The Causes of Welfare State Expansion: Deindustrialization or Globalization? World Politics, 52(3), 313-349. Retrieved from http://www.jstor.org/stable/25054116

Iversen, T., \& Stephens, J. D. (2008). Partisan Politics, the Welfare State and Three Worlds of Human Capital Formation. Comparative Political Studies, 41(4/5), 600-637.

Kenworthy, L. (1999). Do Social-Welfare Policies Reduce Poverty? A Cross-National Assessment. Social Forces, 77(3), 1119-1139. doi:10.1093/sf/77.3.1119

Kenworthy, L. (2007). Toward Improved Use of Regression in Macro-Comparative Analysis. Comparative Social Research, 24, 343-350. Retrieved from http://www.sciencedirect.com/science/bookseries/01956310

Kenworthy, L. (2009). The Effect of Public Opinion on Social Policy Generosity: Research Note. Socio-Economic Review, 7, 727-740.

Kittel, B. (1999). Sense and Sensitivity in Pooled Analysis of Political Data. European Journal of Political Research, 35(2), 225-253. doi:10.1111/1475-6765.00448

Kittel, B. (2006). A Crazy Methodology? On the Limits of Macro-Quantitative Social Science Research. International Sociology, 21(5), 647-677.

Kittel, B., \& Winner, H. (2005). How Reliable is Pooled Analysis in Political Economy? The Globalization-Welfare State Nexus Revisited. European Journal of Political Research, 44(2), 269-293. doi:Article 
Levelt, C., Noort, C., \& Drenth, C. (2012). Flawed science: The fraudulent research practices of social psychologist Diederik Stapel. Tilburg, NL. Retrieved from https://www.commissielevelt.nl/wpcontent/uploads_per_blog/commissielevelt/2013/01/finalreportLevelt1.pdf

Liu, M., \& Stainback, K. (2013). Interviewer Gender Effects on Survey Responses to MarriageRelated Questions. Public Opinion Quarterly, 77 (2 ), 606-618. doi:10.1093/poq/nft019

Macdonald, K. I. (2011). Family Investments in Children: What the Interactions and the Data Do Not Say. European Sociological Review. doi:10.1093/esr/jcr021

McCall, G. J. (1984). Systematic Field Observation. Annual Review of Sociology, 10, $263-282$. doi:10.2307/2083176

Mehrtens III, F. J. (2004). Three Worlds of Public Opinion? Values, Variation, and the Effect on Social Policy. International Journal of Public Opinion Research, 16(2), 115-143.

Myles, J. (2006). Welfare States and Public Opinion: Comment on Brooks and Manza. American Sociological Review, 71(3), 495-498.

OECD. (2010). Gross Domestic Product (Expenditure Approach), Per head, US \$, constant prices, OECD base year. Exact download moment of April 19, 2010, 11:33am GMT GMT.

OECD. (2014). Gross Domestic Product (Expenditure Approach), Per head, US \$, constant prices, constat PPPs, OECD base year. Exact download moment of May 16, 2014, 10:41am GMT.

Presser, S., \& Stinson, L. (1998). Data Collection Mode and Social Desirability Bias in SelfReported Religious Attendance. American Sociological Review, 63(1), 137-145. doi:10.2307/2657486

Roethlisberger, F. J., \& Dickson, W. J. (2003). Management and The Worker. (K. Thompson, Ed.)The Early Sociology of Management and Organizations (Reprint of.). New York: Routledge.

Schaeffer, N. C. (1980). Evaluating Race-of-Interviewer Effects In a National Survey. Sociological Methods \& Research , 8 (4 ), 400-419. doi:10.1177/004912418000800403

Shalev, M. (2007). Limits and Alternatives to Multiple Regression in Comparative Research. Comparative Social Research, 24, 267-314.

Skocpol, T., \& Amenta, E. (1986). States and Social Policies. Annual Review of Sociology, 12, $131-157$. 
Stanley, D. J., \& Spence, J. R. (2014). Expectations for Replications: Are Yours Realistic? . Perspectives on Psychological Science , 9 (3 ), 305-318. doi:10.1177/1745691614528518

Sterling, T. D., Rosenbaum, W. L., \& Weinkam, J. J. (1995). Publication Decisions Revisited: The Effect of the Outcome of Statistical Tests on the Decision to Publish and Vice Versa. The American Statistician, 49(1), 108-112. doi:10.1080/00031305.1995.10476125

Swank, D. H. (1998). Funding the Welfare State: Globalization and the Taxation of Business in Advanced Market Economies. Political Studies, 46(4). doi:Article

Van der Meer, T., Te Grotenhuis, M., \& Pelzer, B. (2010). Influential Cases in Multilevel Modeling: A Methodological Comment . American Sociological Review , 75 (1 ), 173-178. doi: $10.1177 / 0003122409359166$

Van Kolfschooten, F. (2014). Fresh Misconduct Charges Hit Dutch Social Psychology. Science, 344 (6184), 566-567. doi:10.1126/science.344.6184.566

Winship, C., \& Radbill, L. (1994). Sampling Weights and Regression Analysis. Sociological Methods \& Research, 23(2), 230-257. doi:10.1177/0049124194023002004 


\section{Tables}

Table 1. Seemingly Identical Models of Social Policy Preferences impacting Welfare State Spending as a Percentage of Gross Domestic Product, Original and Replicated Data

\begin{tabular}{|c|c|c|c|c|c|c|}
\hline \multirow[b]{2}{*}{ Model I } & $\frac{\text { Brooks a }}{(2006:}$ & $\frac{\text { d Manza }}{\text { able 4) }}$ & $\underline{\text { Kenv }}$ & orthy $^{\text {a }}$ & \multicolumn{2}{|c|}{ 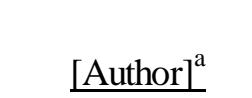 } \\
\hline & Coef. & R.s.e. & Coef. & R.s.e. & Coef. & R.s.e. \\
\hline Constant & $16.42 *$ & $(7.73)$ & -0.39 & $(4.83)$ & 4.23 & $(8.51)$ \\
\hline Year & $0.36^{*}$ & $(0.12)$ & 0.25 & $(0.13)$ & 0.26 & $(0.14)$ \\
\hline Per Capita GDP & $-1.04 *$ & $(0.18)$ & $-0.73^{*}$ & $(0.08)$ & $-0.70 *$ & $(0.14)$ \\
\hline Unemployment & 0.18 & $(0.23)$ & $0.50 *$ & $(0.23)$ & 0.33 & $(0.29)$ \\
\hline Aged Population & 0.50 & $(0.35)$ & 0.66 & $(0.31)$ & 0.65 & $(0.32)$ \\
\hline Women's LFP & $0.24 *$ & $(0.09)$ & $0.34 *$ & $(0.07)$ & 0.26 & $(0.11)$ \\
\hline Political Institutions & $1.84 *$ & $(0.48)$ & $1.17 *$ & $(0.28)$ & 0.40 & $(0.36)$ \\
\hline Religious Party Control & - & - & - & - & - & - \\
\hline Left Party Control & - & - & - & - & - & - \\
\hline Social Policy Preferences & $3.70 *$ & $(0.90)$ & $4.02 *$ & $(0.94)$ & $4.39 *$ & $(0.98)$ \\
\hline $\begin{array}{l}\text { Social Policy Preferences* } \\
\text { Liberal Democracy }\end{array}$ & $-2.35^{*}$ & $(0.92)$ & $-2.55^{*}$ & $(0.95)$ & $-3.94 *$ & $(1.12)$ \\
\hline Net Liberal Democracy Effect ${ }^{b}$ & 1.35 & -- & $1.47 *$ & $(0.36)$ & 0.44 & $(0.35)$ \\
\hline Model II & Coef. & R.s.e. & Coef. & R.s.e. & Coef. & R.s.e. \\
\hline Constant & 2.58 & $(8.59)$ & -9.01 & $(4.94)$ & -3.28 & $(7.90)$ \\
\hline Year & $0.36 *$ & $(0.08)$ & $0.36^{*}$ & $(0.08)$ & $0.31 *$ & $(0.11)$ \\
\hline Per Capita GDP & $-0.66^{*}$ & $(0.20)$ & $-0.52 *$ & $(0.14)$ & -0.47 & $(0.22)$ \\
\hline Unemployment & $0.55^{*}$ & $(0.24)$ & $0.73 *$ & $(0.17)$ & $0.53 *$ & $(0.23)$ \\
\hline Aged Population & 0.31 & $(0.33)$ & 0.44 & $(0.38)$ & 0.46 & $(0.24)$ \\
\hline Women's LFP & $0.30 *$ & $(0.08)$ & $0.38 *$ & $(0.05)$ & $0.29 *$ & $(0.09)$ \\
\hline Political Institutions & 0.77 & $(0.59)$ & 0.45 & $(0.38)$ & -0.12 & $(0.53)$ \\
\hline Religious Party Control & $0.08 *$ & $(0.02)$ & $0.08 *$ & $(0.01)$ & $0.08 *$ & $(0.02)$ \\
\hline Left Party Control & 0.02 & $(0.02)$ & 0.01 & $(0.01)$ & 0.02 & $(0.01)$ \\
\hline Social Policy Preferences & $2.65 *$ & $(0.69)$ & $3.05 *$ & $(0.47)$ & $3.04 *$ & $(0.89)$ \\
\hline $\begin{array}{l}\text { Social Policy Preferences* } \\
\text { Liberal Democracy }\end{array}$ & $-1.77 *$ & $(0.71)$ & $-2.06^{*}$ & $(0.39)$ & $-2.85^{*}$ & $(0.92)$ \\
\hline Net Liberal Democracy Effect ${ }^{b}$ & 0.88 & -- & $1.00 *$ & $(0.26)$ & 0.18 & $(0.37)$ \\
\hline
\end{tabular}

${ }^{\mathrm{a}}$ Means and standard deviations for all variables in Kenworthy and [author] data rescaled to be identical to those used by Brooks and Manza allowing for direct comparis on of effect sizes across models.

${ }^{b}$ Effect size of social policy preferences in liberal democracies. This is not a parameter in the regression. It is the main effect of Social Policy Preferences added to the interaction effect of Social Policy Preferences*Liberal Democracy, with a corresponding test for significant difference from the value zero. The math may appear incorrect at twodecimal places due to rounding error.

$* \mathrm{p}<.05 ;$ R.s.e. $=$ Robust clustered standard errors. 
Table 2. The Estimated Size of Secondary Observer Effects based on Variation in Measures

Differences between Seemingly Identical Measures ( $\mathrm{N}=43)$

\begin{tabular}{lccccc}
\hline Social Welfare Spending & Mean $^{\mathrm{c}}$ & s.d. & Min & Max & Pearson's r \\
[Author] - Kenworthy & 0 & 1.97 & -7.45 & 2.86 & 0.929 \\
[Author] - CWS (B\&M) & 0 & 1.78 & -3.39 & 5.61 & 0.942 \\
CWS - Kenworthy & 0 & 1.89 & -8.32 & 4.31 & 0.935 \\
Social Policy Preferences $^{a}$ & & & & & \\
Post Factor - Kenworthy (B\&M) & 0 & 0.35 & -1.54 & 0.28 & 0.983 \\
Pre Factor - Kenworthy (B\&M) & 0 & 0.36 & -1.62 & 0.27 & 0.982 \\
Post Factor - Pre Factor & 0 & 0.13 & -0.13 & 0.65 & 0.998 \\
Unweighted - Post Factor & 0 & 0.11 & -0.63 & 0.11 & 0.998 \\
Control Variables & & & & & \\
GDP Per Capita & 0 & 0.11 & -0.27 & 0.36 & 0.993 \\
Unemployment & 0 & 0.32 & -0.86 & 0.68 & 0.948 \\
Aged Population & 0 & 0.16 & -0.64 & 0.46 & 0.987 \\
Women's LFP & 0 & 0.22 & -0.58 & 0.44 & 0.976 \\
Political Institutions & 0 & 0.37 & -0.62 & 1.18 & 0.932 \\
Religious Party Control & 0 & 0.41 & -1.76 & 1.87 & 0.916 \\
Left Party Control & 0 & 0.72 & -2.12 & 2.23 & 0.743 \\
Average of Above Scores - An Estimation & of Secondary Observer Effects & & \\
Social Welfare Spending & 0 & $\mathbf{1 . 8 8}$ & -6.39 & 4.26 & -- \\
Social Policy Preferences & 0 & $\mathbf{0 . 2 4}$ & -0.98 & 0.33 & -- \\
Control Variables & 0 & $\mathbf{0 . 3 2}$ & -0.98 & 1.03 & -- \\
\hline
\end{tabular}

${ }^{a}$ Variations of social policy preferences measures: Data weighted and predicted from factor analysis after collapsing individual data to country-means ("Post"), weighted and predicted before collapsing to country-means ("Pre"), unweighted and predicted after ("Unweighted").

${ }^{\mathrm{b}}$ Control variables calculated as the difference between [Author]'s and Kenworthy's data.

${ }^{\mathrm{c}}$ All variables standardized to a mean of zero. Social welfare spending and social policy preferences adjusted to B\&M s.d.; all control variables adjusted to s.d. = one.

${ }^{\mathrm{d}}$ Mean and s.d. of all difference scores calculated from all variables standardized (mean=0; s.d.=1). 
Table 3. Simulations of Secondary Observer Effects

A. Simple Monte Carlo Simulation of regressions presented in Table 1 where normally distributed pseudo-random errors are added to the dependent variable Social Welfare Spending $(m=0, s . d .=0.24)$ and the primary independent variable Social Policy Preferences $(m=0, s . d .=1.88)$. Each of these two variables has 3 different starting values in the simulation (see Table 2), therefore there are 9 possible combinations of starting values. The simulation is run 1,000 times for each starting combination yielding 18,000 simulations.

\begin{tabular}{lcccc} 
Simulation A & & \multicolumn{3}{c}{ Hypothesis Test Rejection Rate } \\
\cline { 2 - 5 } & $\mathrm{N}$ & $\mathrm{H} 1$ & $\mathrm{H} 2$ & $\mathrm{H} 3$ \\
\hline Model I & 9,000 & $1 \%$ & $28 \%$ & $62 \%$ \\
Model II & 9,000 & $16 \%$ & $45 \%$ & $72 \%$ \\
Model I \& Model II & 18,000 & $8 \%$ & $36 \%$ & $67 \%$ \\
\hline \hline
\end{tabular}

B. Otherwise similar to Simulation A above with the addition of normally distributed pseudo-random errors for all control variables $(m=0$, s.d. $=0.32)$ where the standard deviation of the error is re-scaled to the size of each control variable's standard deviation.

\begin{tabular}{lcccc} 
Simulation B & & \multicolumn{3}{c}{ Hypothesis Test Rejection Rate } \\
\cline { 2 - 5 } & $\mathrm{N}$ & $\mathrm{H} 1$ & $\mathrm{H} 2$ & $\mathrm{H} 3$ \\
\hline Model I & 9,000 & $10 \%$ & $57 \%$ & $79 \%$ \\
Model II & 9,000 & $48 \%$ & $74 \%$ & $84 \%$ \\
Model I \& Model II & 18,000 & $29 \%$ & $66 \%$ & $81 \%$ \\
\hline
\end{tabular}

${ }^{a}$ Percentage rejection of the null hypothesis that the coefficient $=0$ at $\mathrm{p}<.05$, two-tailed. H1 tests coefficients for Social Policy Preferences in social and Christian democracies. H2 tes ts the Social Policy Preferences coefficients in liberal democracies as $=$ to coefficients in social and Christian democracies. $\mathrm{H} 3$ tests that the Social Policy Preferences coefficient for the effect in liberal democracies is significantly different from zero. 
Appendix 1. Comparison of three Datasets using Seemingly Identical Sources of Measurement $(\mathrm{N}=43)$

\begin{tabular}{lccccc}
\hline & \multicolumn{1}{c}{ B\&M } & & Kenworthy & & [Author] \\
\cline { 2 - 2 } Variable & Mean (SD) & & Mean (SD) & & Mean (SD) \\
\hline Social Welfare Spending & $21.53(5.23)$ & & $21.65(5.19)$ & & $20.45(5.05)$ \\
Per capita GDP & $-0.01(1.88)$ & & $-0.01(1.88)$ & & $0.00(1.00)$ \\
Unemployment Rate & $21.98(3.59)$ & & $25.42(4.39)$ & & $24.93(4.28)$ \\
Aged Population & $7.33(2.91)$ & & $7.04(2.72)$ & & $7.43(2.83)$ \\
Women's Labor Force Participation & $62.50(8.32)$ & & $63.02(8.44)$ & & $62.07(8.25)$ \\
Veto Points & $14.16(2.11)$ & & $14.43(2.17)$ & & $14.33(2.15)$ \\
Religious Party Control & $0.03(1.52)$ & & $0.00(1.94)$ & & $0.00(1.29)$ \\
Left Party Control & $16.00(28.48)$ & & $15.16(26.91)$ & & $15.71(28.22)$ \\
\hline
\end{tabular}

